\title{
Voltammetric Detection of Lead Using Chitosan-tripolyphosphate Crosslinked Electrode
}

\author{
Mônika G. Heineman, * Bruna L. GonÇalves, ** Juliano R. M. ViCEnTI, ${ }^{* *}$ and Daiane Dias*† \\ *Laboratório de Eletro-Espectro Analítica (LEEA), Escola de Química e Alimentos, Universidade Federal do \\ Rio Grande, Av. Itália, km 8, Rio Grande, 96203-900, RS, Brazil \\ **Laboratório de Físico-Química Aplicada e Tecnológica (LAFQAT), Escola de Química e Alimentos, \\ Universidade Federal do Rio Grande, Av. Itália, km 8, Rio Grande, 96203-900, RS, Brazil
}

\begin{abstract}
This paper discusses about the improvement of electrochemical characteristics of graphite paste electrode chemically modified with chitosan through physical crosslinking of the biopolymer with sodium tripolyphosphate. Biopolymer characterizations were performed by scanning electron microscopy, Fourier transform infrared spectroscopy, cyclic voltammetry and electrochemical impedance spectroscopy. The electrochemical characterization of $\mathrm{Pb}$ with graphite paste electrode modified with chitosan crosslinked with sodium tripolyphosphate (GPE-CTS-TPP) showed that the process is quasireversible, controlled by adsorption and involves the transfer of two electrons. Additionally, the physical crosslinking process decreased the electrode resistance as well as improved the electron transfer rate. Once the GPECTS-TPP showed enhanced morphological and electrochemical characteristics, it was applied for Pb determination by square wave anodic stripping voltammetry. The method presented appropriate accuracy (recoveries from 95 to $108 \%$ and concordance with comparative method between 90 and 107\%), high sensitivity (limit of detection and quantification of $\mathrm{Pb}$ were 0.73 and $2.44 \mu \mathrm{g} \mathrm{L}^{-1}$, respectively) and could be applied to analytical determinations.
\end{abstract}

Keywords Chitosan physically crosslinked, sodium tripolyphosphate, lead, adsorption, voltammetry

(Received June 29, 2019; Accepted July 23, 2019; Advance Publication Released Online by J-STAGE August 2, 2019)

\section{Introduction}

Electrode development has become an important tool for electroanalytical chemists mainly due to the sensitivity in determinations, moderate cost and portability. ${ }^{1}$ Hence, chemically modified electrodes (CME) have been widely applied due to the possible acceleration of electron transfer reaction or preferential accumulation, promoting better selectivity, sensitivity and/or stability for the electrodes ${ }^{2}$ with a satisfactory response for several purposes and applications. ${ }^{3-6}$

Among the modifiers applied for this purpose, we highlight chitosan (CTS), a biodegradable linear polysaccharide obtained from the deacetylation of chitin, which is obtained from a natural source, for example, the exoskeleton of crustaceans. ${ }^{5,7}$ CTS presents high complexing capacity and excellent adsorption rate for inorganic and organic compounds, since the amine and hydroxyl groups present in its structure can act as coordination sites. ${ }^{8,9}$ In special cationic compounds, such as metals, it can be adsorbed by chelating through the amine groups in neutral solutions ${ }^{10}$ and in the anionic compounds, such as dyes, it can be adsorbed due to the electrostatic forces generated by the amine groups protonated in acid solution. ${ }^{9}$ The interactions that occur between these compounds and the CTS can be used for several purposes, such as decontamination of effluents and development of CMEs. ${ }^{11,12}$

$\dagger$ To whom correspondence should be addressed.

E-mail: daianezd@gmail.com
The CTS adsorption capacity as well as its stability can be easily improved through chemical or physical crosslinking processes. ${ }^{13,14}$ The physical crosslinking process can be highlighted by using agents (e.g. sodium tripolyphosphate (TPP)) with low toxicity and that do not require strict handling and storage restrictions when compared to glutaraldehyde and epichlorohydrin (agents used in chemical crosslinking process). ${ }^{15}$ In acid conditions, TPP increases the medium ionic strength and promotes the ionic interaction between its anionic groups (phosphate group) and protonates the amino groups (from $\mathrm{NH}_{2}$ to $\mathrm{NH}_{3}{ }^{+}$) of the CTS. ${ }^{16,17}$

Due to the aforementioned, CTS as well as crosslinked CTS has been used for CME development ${ }^{18-21}$ and can be immobilized on solid or carbon paste electrodes (CPE) through adsorption, covalent bonding and occlusion. . $^{3,19,22,23}$ The solid electrodes have some disadvantages, such as high cost and memory effect, for which polishing and cleaning steps prior to immobilization are required. ${ }^{24} \mathrm{CPE}$ modification has been increasing due to its low cost, easy renovation and preparation only by simple mixture of conductor, chemical modifier and binder generating a material with low current background, wide potential range, chemical inertia and wide application..$^{19,25,26}$ However, the chemical modification of CPE must be carefully evaluated, once the electron transfer kinetics depend on the structure and surface preparation, that could make the electrochemical reactions slower in the carbon than in metallic electrodes. ${ }^{27,28}$ Among the conductors normally used, carbon black and graphite deserve special attention due to their excellent conductivity, wide potential range and chemical inertia. ${ }^{29,30,31}$ Although the 
physical crosslinking procedure of CTS is known, to the best of our knowledge, there are no studies that deal with the interpretation of the spectroscopic, morphological and electrochemical responses of this material combined with graphite applied to CME development. Therefore, the aim of the work is to evaluate the physical crosslinking of CTS with TPP (sodium tripolyphosphate) and provide material characterization by scanning electron microscopy, Fourier transform infrared spectroscopy, cyclic voltammetry and electrochemical impedance spectroscopy techniques to contribute to further development of $\mathrm{CME}$ for application to $\mathrm{Pb}$ determination.

\section{Experimental}

\section{Chemicals, standard solutions and samples}

The following chemicals were used: nitric acid 65\% (Vetec, Brazil), acetic acid (Neon, Brazil), sodium hydroxide (Dinâmica, Brazil), chitosan (Sigma-Aldrich, USA), graphite powder (Sigma-Aldrich, USA), sodium tripolyphosphate (SigmaAldrich, USA), mineral oil (Sigma-Aldrich, USA), potassium ferrocyanide (ISOFAR, Brazil), palladium nitrate II (SpecSol, Brazil) and potassium bromide (Sigma-Aldrich, USA). The standard solution used was $\mathrm{Pb}$ (SpecSol, Brazil). Ultrapure water from a Millipore water purified system $\left(18.2 \mathrm{M} \Omega \mathrm{cm}^{-1}\right.$, Milli-Q Direct-Q UV3, Germany) was used in all assays.

The samples analyzed in this work, as well as those used for the validation of the methods, were purchased on at the local commercial market in the city Rio Grande, Rio Grande do Sul ( 4 of sparkling and 4 of still mineral water of different brands).

\section{CTS crosslinked with TPP procedure}

Initially, $1 \%(\mathrm{w} / \mathrm{v})$ of CTS was dissolved in $1 \%(\mathrm{v} / \mathrm{v})$ of aqueous acetic acid solution at room temperature $\left(25^{\circ} \mathrm{C}\right)$ then $10 \mathrm{~mL}$ of $2 \%$ TPP solution (w/v) was added, and the solution was maintained under magnetic stirring for $15 \mathrm{~min} .{ }^{32}$ The solid formed was centrifuged for $30 \mathrm{~min}$ at $5000 \mathrm{rpm}$, the supernatant was removed and the material was lyophilized. ${ }^{33}$

\section{Instrumentation}

Fourier transform infrared spectroscopy (FT-IR). Vibrational analysis by FT-IR was performed using a Shimadzu IR PRESTIGE-21 spectrophotometer. Solid samples were gently ground and mixed with some spectroscopic grade potassium bromide and submitted for analysis using the diffuse reflectance method (DRIFTS). Spectroscopic data were registered from 4000 to $400 \mathrm{~cm}^{-1}$ considering a resolution of $4 \mathrm{~cm}^{-1}$.

Scanning electron microscopy (SEM). SEM images were obtained using a JEOL JSM 6610 LV instrument. Samples were deposited on a stub and coated using a Denton vacuum carbon coater prior to exposure (120 s of exposure with $50 \mathrm{~mA}$ ).

Cyclic voltammetry $(\mathrm{CV})$. These experiments were performed by Potenciostat/Galvanostat PGSTAT $302 \mathrm{~N}$ and Interface IME 663 (Autolab, Netherlands) using $27 \mathrm{~mL}$ of electrolyte $\left(\mathrm{HNO}_{3} 0.15\right.$ $\mathrm{mol} \mathrm{L}^{-1}$ ) and $100 \mathrm{mg} \mathrm{L}^{-1}$ of $\mathrm{Pb}$. Scan rate from 10 to $100 \mathrm{mV} \mathrm{s}^{-1}$, with start potential $\left(E_{\text {start }}\right)$ of $-0.8 \mathrm{~V}$, vertex potential of $-0.2 \mathrm{~V}$ and end potential $\left(E_{\text {end }}\right)$ of $-0.8 \mathrm{~V}$ were evaluated. A three-electrode configuration consisted of graphite paste electrode modified with chitosan crosslinked with sodium tripolyphosphate (GPE-CTS-TPP) as working electrode, $\mathrm{Ag} / \mathrm{AgCl}\left(\mathrm{KCl} 3 \mathrm{~mol} \mathrm{~L}^{-1}\right)$ and platinum as reference and counter electrodes, respectively. Electrochemical impedance spectroscopy (EIS). Measurements were performed by Potentiostat/Galvanostat PGSTAT 302N, equipped with the FRA32M electrochemical impedance spectroscopy module (Autolab, Netherlands). EIS measurements were performed using the following parameters: half wave potential $-0.4 \mathrm{~V}$, sine wave amplitude of $10 \mathrm{mV}$ (RMS), 10 points/decade and frequency between $100 \mathrm{kHz}$ and $100 \mathrm{mHz}$. Both cases were controlled by NOVA 2.1 software.

Comparative method. The comparative method analyses were performed with a high-resolution continuum source graphite furnace atomic absorption spectrometer (HR-CS GF AAS), Model ContrAA 700 (Analytik Jena, Germany), operated with graphite tubes coated with pyrolytic graphite, integrated platform system, xenon short-arc lamp as radiation source (the line monitored was $283.30 \mathrm{~nm}$ ) and argon as purge gas (White Martins, Brazil) with a flux of $2.0 \mathrm{~L} \mathrm{~min}^{-1}$. The pyrolysis and atomization temperatures applied were 1000 and $2000^{\circ} \mathrm{C}$, respectively. The calibration curve was prepared daily $(10,25$, 50,75 and $\left.100 \mu \mathrm{g} \mathrm{L}^{-1}\right)$. The analyzes were performed using $20 \mu \mathrm{L}$ of sample and/or $\mathrm{Pb}$ standard solutions with $5 \mu \mathrm{L}$ of the modifier $\mathrm{Pd}\left(\mathrm{NO}_{3}\right)_{2}\left(1000 \mathrm{mg} \mathrm{L}^{-1}\right)$.

\section{Parameters evaluated for construction of electrode modified with CTS and optimization of voltammetric parameters}

Preliminarily, $0.210 \mathrm{~g}$ of graphite $(70 \% \mathrm{w} / \mathrm{w})$ was mixed with $0.015 \mathrm{~g}$ of CTS or CTS crosslinked with TPP $(5 \% \mathrm{w} / \mathrm{w})$ and $0.075 \mathrm{~g}$ of binder $(25 \% \mathrm{w} / \mathrm{w}$ of mineral oil $)$ with a pestle in a mortar for $40 \mathrm{~min}$. The obtained paste was inserted in a syringe (90 $\mathrm{mm}$ in height and internal tip diameter of approximately $2.6 \mathrm{~mm}$ ) and a copper wire was used as electric contact. Then, the modifier $(5,10$ or $15 \%$ w/w of CTS crosslinked with TPP) and mineral oil proportion $(15,20$ or $25 \% \mathrm{w} / \mathrm{w})$ were varied, keeping the graphite concentration $(70 \% \mathrm{w} / \mathrm{w})$. Finally, using the result of the best proportion, the carbon black and graphite (conductors) were evaluated, as well as the electrolyte concentration influence $\left(\mathrm{HNO}_{3} 0.01,0.05,0.1,0.15 ; 0.20\right.$ and $\left.0.25 \mathrm{~mol} \mathrm{~L}^{-1}\right)$ in the voltammetric response. The voltammetric parameters evaluated were potential deposition $\left(E_{\mathrm{dep}}\right)$ (from -0.60 to $-1.3 \mathrm{~V}$ ), frequency (from 10 to $90 \mathrm{~Hz}$ ) and amplitude (from 0.01 to $0.15 \mathrm{~V}$ ). All these experiments were performed by square wave anodic stripping voltammetry (SWASV) using $27 \mathrm{~mL}$ of electrolyte $\left(\mathrm{HNO}_{3}\right), 250 \mu \mathrm{g} \mathrm{L}^{-1}$ of $\mathrm{Pb}$, scan rate of $270 \mathrm{mV} \mathrm{s}^{-1}$, start potential $\left(E_{\text {start }}\right)$ of $-0.8 \mathrm{~V}$, end potential $\left(E_{\text {end }}\right)$ of $-0.1 \mathrm{~V}, E_{\text {dep }}$ of $-1.1 \mathrm{~V}$, deposition time $\left(t_{\text {dep }}\right)$ of $30 \mathrm{~s}$, frequency of $60 \mathrm{~Hz}$ and amplitude of $0.06 \mathrm{~V}$. The limit of detection (LOD) and limit of quantification (LOQ) of the proposed method were calculated as being 3 times the standard deviation $(n=10)$ for the blank solution (supporting electrolyte) divided by the analytical curve slope and 10 times the standard deviation $(n=10)$ for the blank solution (supporting electrolyte) divided by the analytical curve slope, respectively.

\section{Application of GPE-CTS-TPP to Pb determination by SWASV}

$\mathrm{Pb}$ voltammetric determinations were performed by SWASV using $23 \mathrm{~mL}$ of sample and $4 \mathrm{~mL}$ of $\mathrm{HNO}_{3} 1 \mathrm{~mol} \mathrm{~L}^{-1}$. The voltammetric parameters used were $E_{\text {dep }}$ of $-1.1 \mathrm{~V}, t_{\text {dep }}$ of $1020 \mathrm{~s}$, $E_{\text {start }}$ of $-0.9 \mathrm{~V}, E_{\text {end }}$ of $-0.1 \mathrm{~V}, E_{\text {step }}$ of $0.005 \mathrm{~V}$, amplitude of $0.09 \mathrm{~V}$ and frequency of $80 \mathrm{~Hz}$. The measurements were performed in triplicate and the calibration method applied was standard addition from 10 to $80 \mu \mathrm{g} \mathrm{L}^{-1}$ (addition of $90 \mu \mathrm{L}$ of $3 \mathrm{mg} \mathrm{L}^{-1} \mathrm{~Pb}$ solution). It is important to mention that between the measurements the electrode surface was cleaned with paste abrasive removal on sulfite paper.

\section{Results and Discussion}

Spectroscopic and morphologic characterization of biopolymers FT-IR spectroscopy was employed for characterization of CTS 


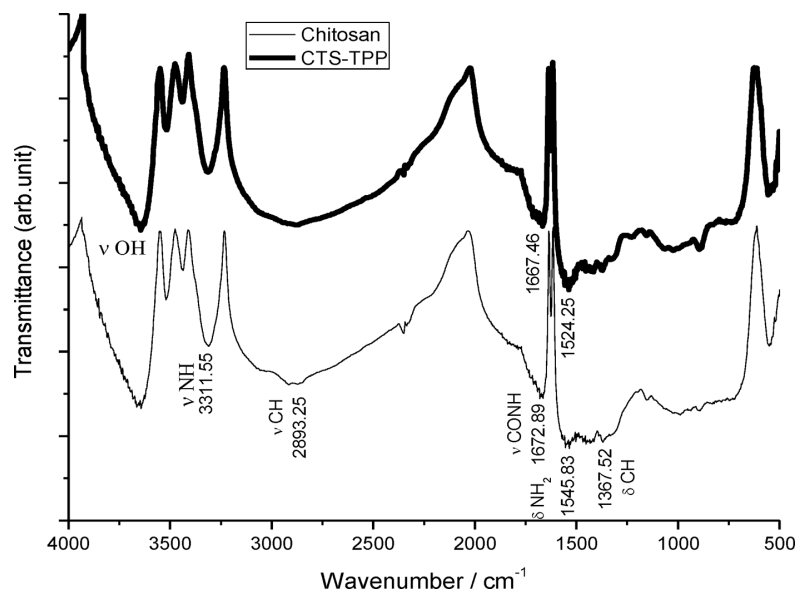

Fig. 1 FT-IR spectra of CTS and CTS-TPP.

and CTS crosslinked with TPP. For the CTS (thin line spectrum in Fig. 1), absorption bands around $3500 \mathrm{~cm}^{-1}$ are related to $\mathrm{O}-\mathrm{H}$ stretching of hydroxyl groups, ${ }^{34}$ although absorption at $3311.55 \mathrm{~cm}^{-1}$ is attributable to $\mathrm{N}-\mathrm{H}$ stretching. ${ }^{35}$ The symmetric $\mathrm{C}-\mathrm{H}$ stretching and $\mathrm{C}-\mathrm{H}$ deformations are observed at 2893.25 and $1367.52 \mathrm{~cm}^{-1}$, respectively. ${ }^{34}$ In the spectrum registered for CTS crosslinked with TPP, an observation is made for a negative shift of CONH stretching absorption band at $1672.89 \mathrm{~cm}^{-1}$ in CTS to $1667.46 \mathrm{~cm}^{-1}$ in CTS-TPP product (thick line spectrum in Fig. 1). Additionally, there is a second negative shift involving $\mathrm{N}-\mathrm{H}$ angular deformation at $1545.83 \mathrm{~cm}^{-1}$ in CTS moving to $1524.25 \mathrm{~cm}^{-1}$ in CTS-TPP. These shifts in absorption bands are compatible with that described previously ${ }^{35}$ and are indicative of CTS interaction with phosphate ions of TPP. ${ }^{36}$

The EIS is often used to obtain information on the electrochemical characteristics of different materials applied to CMEs development. ${ }^{37}$ The results obtained are associated with an electrical circuit, in which it is possible to distinguish some parameters such as diffusion impedance, ionic conductivity, double layer electric capacitance, electronic transfer resistance and load transport processes. ${ }^{38}$ Figure 2 shows the Nyquist diagram for impedance measurements using the GPE-CTS and the GPE-CTS-TPP, and it is possible to observe that both electrodes presented the typical format of the Nyquist diagram. ${ }^{39}$ The GPE-CTS presented a semicircle with a huge diameter, which indicates that there is a high resistance to the transfer of charge between the $\mathrm{K}_{4} \mathrm{Fe}(\mathrm{CN})_{6}$ and the surface of the electrode, as well as a slow rate of exchange of electrons. ${ }^{40}$ However, the GPE-CTS-TPP presented a much smaller semicircle, compared to the GPE-CTS, indicating that the surface of this electrode presents lower resistance and higher electron transfer rates between the electrode surface and the $\mathrm{K}_{4} \mathrm{Fe}(\mathrm{CN})_{6}{ }^{40,41}$ This may have occurred because TPP crosslinking provides greater stability and physical property to the CTS polymer network, which enables a better intercalation of the analyte in the matrix. ${ }^{42}$

The SEM micrograph obtained for CTS (Fig. 3a) revealed a more disorganized surface when compared to crosslinked CTS (Fig. 3b). The micrograph of CTS-TPP shown a surface that was smoother and more compact when compared to CTS micrograph (Fig. 3a). Comparable results were reported by Eladlani et al. ${ }^{33}$ for CTS particles crosslinked with TPP. ${ }^{33}$ This surface profile may be interesting for the electrochemical and voltammetric measurements, since it could increase the sensitivity of the electrode in relation to redox processes. This better voltammetric response observed after TPP crosslinking when compared to CTS without crosslinking will be discussed later.

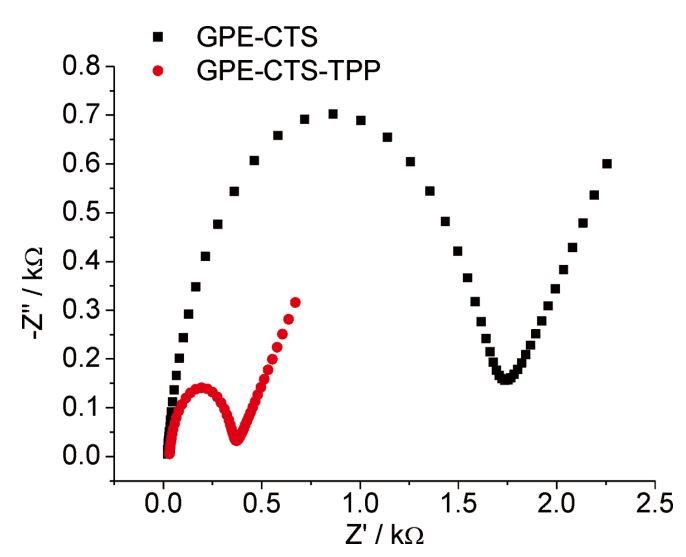

Fig. 2 Nyquist diagram for EIS measurements of electrodes GPECTS and GPE-CTS-TPP.
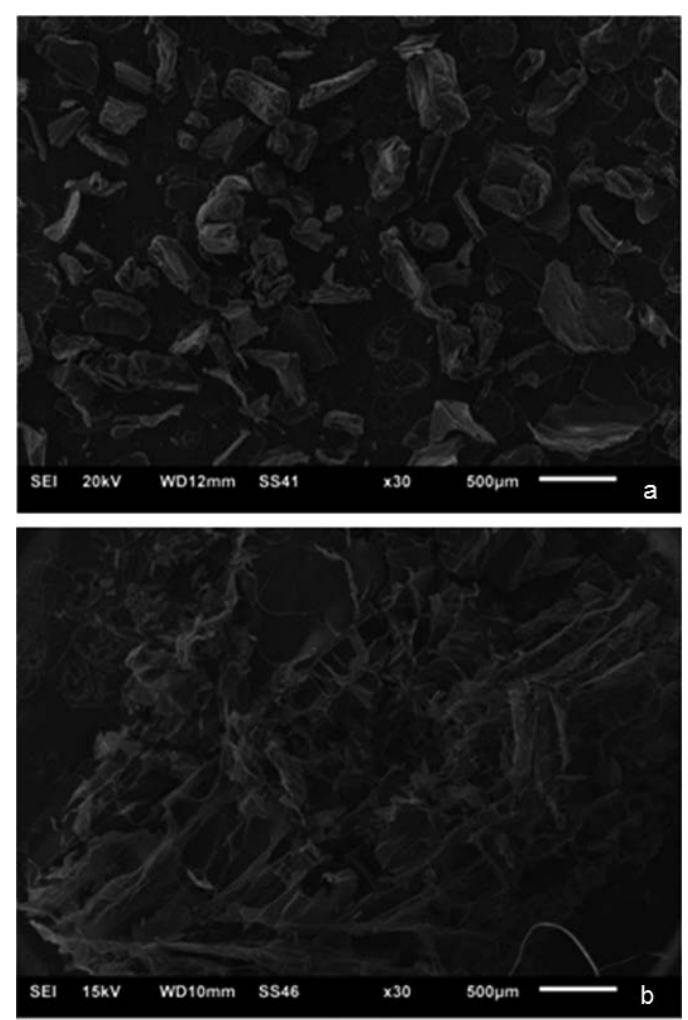

Fig. 3 Micrographics of CTS (a) and CTS-TPP (b).

Kinetic evaluation and electrochemical characterization of $\mathrm{Pb}$ with GPE-CTS-TPP

Considering that there are two electrons transferred in $\mathrm{Pb}$ redissolution (see Voltammetric evaluations of CTS-based modified electrodes section) and since the oxidation and reduction peaks potentials $(-0.45$ and $-0.58 \mathrm{~V}$, respectively) obtained with different scan rate (Fig. 4) presents a peak-topeak separation $(\Delta E)$ near to $65 \mathrm{mV}$ per electron, it can be inferred that the $\mathrm{Pb}$ redox process in the GPE-CTS-TPP is quasireversible. ${ }^{43}$ In addition, it was possible to verify that with the increasing of scan rate, there is a variation of $\mathrm{Pb}$ cathodic peak potential to more negative values and the ratio between anodic and cathodic peak currents was different from 1 , confirming that the process is quasireversible. ${ }^{44}$ Additionally, we have also evaluated the curve correlation obtained from the 


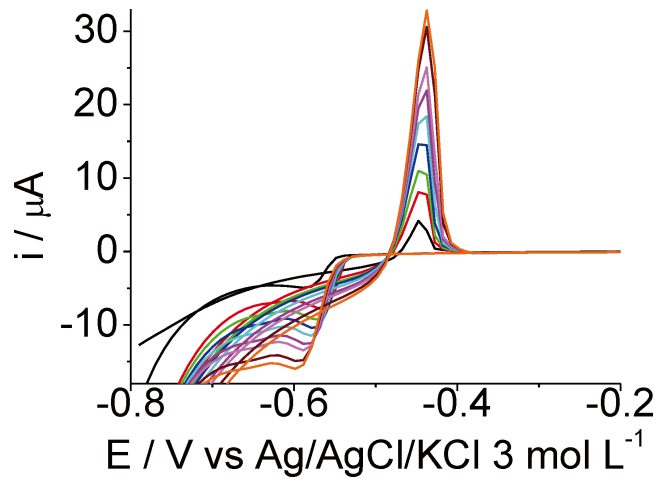

Fig. 4 Cyclic voltammograms for the anodic stripping of $\mathrm{Pb}$ at scan rates of 10 to $100 \mathrm{mV} \mathrm{s}^{-1}$. Experimental conditions: $100 \mathrm{mg} \mathrm{L}^{-1} \mathrm{of} \mathrm{Pb}$, $E_{\text {initial }}=-0.8 \mathrm{~V}, E_{\text {return }}=-0.2 \mathrm{~V}, E_{\text {end }}=-0.8 \mathrm{~V}$ and electrolyte support $=$ $\mathrm{HNO}_{3} 0.15 \mathrm{~mol} \mathrm{~L}^{-1}$.
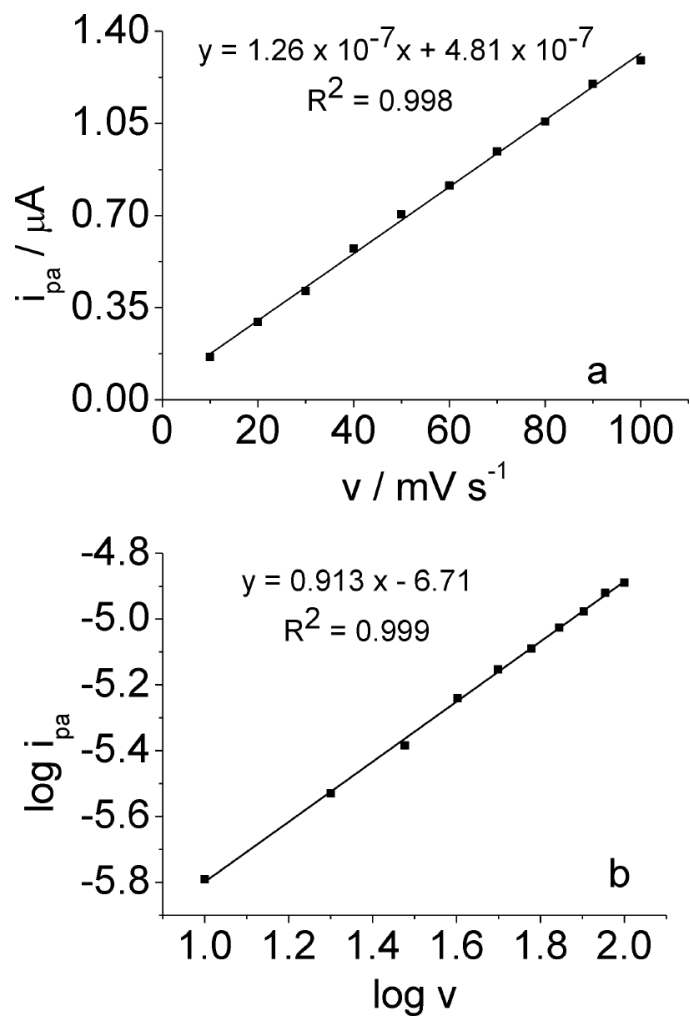

Fig. 5 Graphs obtained through the relationship between (a) $i_{\text {pa }} v s . v$ and (b) $\log i_{\mathrm{pa}} v s$. $\log v$ with scan rates of 10 to $100 \mathrm{mV} \mathrm{s}^{-1}$ and $100 \mathrm{mg} \mathrm{L}^{-1}$ of $\mathrm{Pb}$.

relation between $i_{\mathrm{pa}}$ and scan rate ( $v$ ) (Fig. 5a) and $\log i_{\mathrm{pa}} v s . \log v$ (Fig. 5b) showing that $i_{\mathrm{pa}}$ increases linearly with scan rate $\left(r^{2}=0.998\right)$ and the angular coefficient obtained in Fig. 5b is close to $1(0.913)$ indicating that the process is controlled by adsorption, ${ }^{43,44}$ evidencing the possibility of the use of CTS crosslinked with TPP as adsorbent due to the chemical interaction that occurs between the polymer and the $\mathrm{Pb}$.

Voltammetric evaluations of CTS-based modified electrodes

In the voltammogram depicted in Fig. 6 (as well as in the inset it) is possible to observe that the $\mathrm{Pb}$ current response in the graphite electrode based with CTS-TPP is higher than with only CTS, suggesting the higher $\mathrm{Pb}$ affinity with the crosslinked CTS. When TPP crosslinking agent is used, the crosslinking

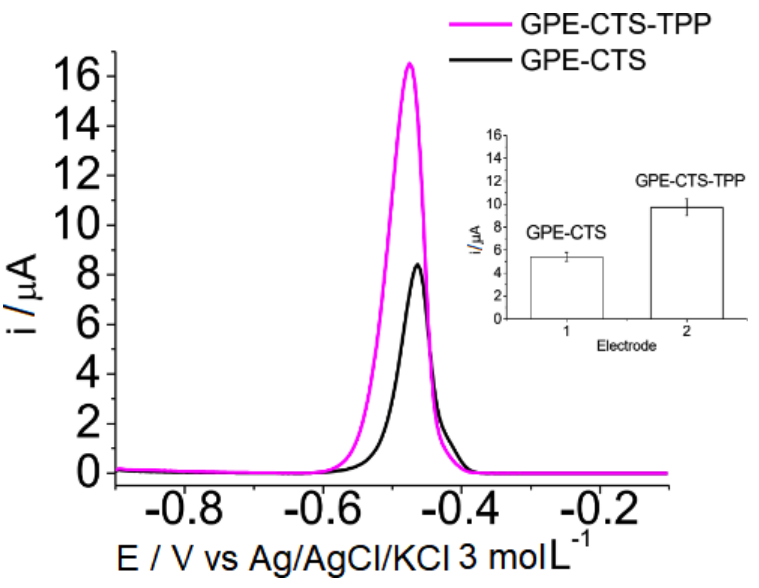

Fig. $6 \mathrm{~Pb}$ voltammograms obtained by SWASV with GPE-CTS and GPE-CTS-TPP. Experimental conditions: $250 \mu \mathrm{g} \mathrm{L}-1$ of $\mathrm{Pb}, \mathrm{HNO}_{3}$ $0.15 \mathrm{~mol} \mathrm{~L}^{-1}, v=270 \mathrm{mV} \mathrm{s}^{-1}, E_{\text {dep }}=-1.1 \mathrm{~V}, t_{\text {dep }}=30 \mathrm{~s}, E_{\text {start }}=-0.9 \mathrm{~V}$ and $E_{\text {end }}=-0.1 \mathrm{~V}$, frequency $=60 \mathrm{~Hz}$ and amplitude $=0.06 \mathrm{~V}$. Inset: $\mathrm{Pb}$ current values obtained with each electrode.

takes place in the amino groups available in the CTS, leaving the hydroxyls free for the adsorption of metals. ${ }^{33}$ Given that $\mathrm{Pb}$ interacts with $\mathrm{OH}$ groups, it is suggested that the peak oxidation current values obtained for the compound in CTS-TPP are higher once there is a greater amount of hydroxyl groups available than in CTS.

In the literature, some studies propose the reaction between metallic compounds with the same $\mathrm{Pb}$ oxidation number ${ }^{45-48}$ and CTS or CTS crosslinked, and the proposed reactions with $\mathrm{Pb}$ are described from 1 to 3 .

$$
\begin{aligned}
& \mathrm{Pb}^{2+}{ }_{(\mathrm{aq})}+\mathrm{CTS}-\mathrm{TPP} \longleftrightarrow\left[\mathrm{Pb}^{2+}-\mathrm{CTS}-\mathrm{TPP}\right] \\
& {\left[\mathrm{Pb}^{2+}-\mathrm{CTS}-\mathrm{TPP}\right]+2 \mathrm{e}^{-} \longleftrightarrow\left[\mathrm{Pb}^{0}-\mathrm{CTS}-\mathrm{TPP}\right]} \\
& {\left[\mathrm{Pb}^{0}-\mathrm{CTS}-\mathrm{TPP}\right] \longleftrightarrow \mathrm{Pb}^{2+}{ }_{(\mathrm{aq})}+2 \mathrm{e}^{-}+\mathrm{CTS}-\mathrm{TP}}
\end{aligned}
$$

The proposed reactions are based on the $\mathrm{Pb}$ complexation with CTS crosslinked with TPP present in the electrode surface (1). In reaction (2), the $\mathrm{Pb}^{2+}$ ions that are complexed in the electrode surface are reduced (at cathodic potential of $-0,58 \mathrm{~V}$ ) to $\mathrm{Pb}^{0}$ and then, in the anodic redissolution step (3), the oxidation from $\mathrm{Pb}^{0}$ to $\mathrm{Pb}^{2+}$ occurs at $-0.53 \mathrm{~V}$ as depicted in Fig. 4. Graphite and carbon black were evaluated as conductors (Fig. S1, Supporting Information) and the highest $\mathrm{Pb}$ current was achieved using graphite $(12 \mu \mathrm{A} \pm 1.76)$ instead of carbon black $(8.85 \mu \mathrm{A} \pm$ 0.82), although both are being used for their good conductance ${ }^{36,49,50}$ and chemical inertia. ${ }^{29}$ Taking into account that graphite presented better results, that is, it is less sensitive to chemical agents ${ }^{31}$ and presents higher purity when compared to carbon black, ${ }^{51}$ it was used as conductor applied in our CME.

After that, the proportion of modifier in the electrode and the influence of the electrolyte concentration were evaluated. In this step, the graphite ratio was fixed $(70 \% \mathrm{w} / \mathrm{w})$ once the decrease in the conductor percentage can compromise the electronic transfer and, consequently, reduce the analyte current response. ${ }^{46}$ Figure 7 shows that in the proportion of CTS-TPP: binder in the CPE varied in the ratio of 5:25, 10:20 and 15:15 and the anodic peak currents $\left(i_{\mathrm{pa}}\right)$ obtained were $20.2 \pm 0.2$, $15.3 \pm 0.1$ and $11.1 \pm 0.4 \mu \mathrm{A}$, respectively. As observed, the greatest current magnitude was obtained with the graphite:CTSTPP:binder in the ratio of 70:5:25 (\% w/w) and it is believed 


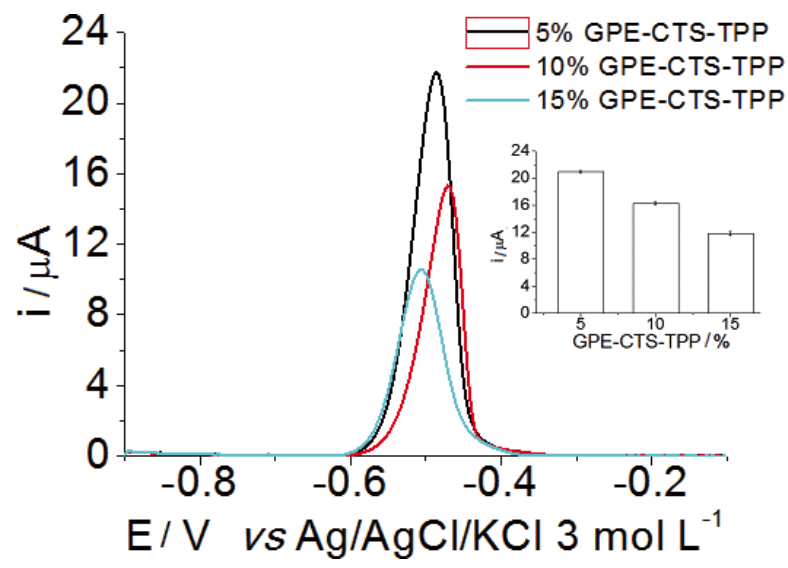

Fig. $7 \mathrm{~Pb}$ voltammograms obtained by SWASV with different proportions of CTS-TPP and binder. Experimental conditions: $250 \mu \mathrm{g} \mathrm{L}^{-1}$ of $\mathrm{Pb}, \mathrm{HNO}_{3} 0.15 \mathrm{~mol} \mathrm{~L}^{-1}, v=270 \mathrm{mV} \mathrm{s}^{-1}, E_{\text {dep }}=-1.1 \mathrm{~V}$, $t_{\text {dep }}=30 \mathrm{~s}, E_{\text {start }}=-0.9 \mathrm{~V}$ and $E_{\text {end }}=-0.1 \mathrm{~V}$, frequency $=60 \mathrm{~Hz}$ and amplitude $=0.06 \mathrm{~V}$. Inset: $\mathrm{Pb}$ current values obtained with each electrode.

that the analytical signal decreased when 10 and $15 \% \mathrm{w} / \mathrm{w}$ of the CTS-TPP was used due to the lower amount of binder present (20 and 15\% w/w, respectively), therefore this impaired the compaction causing the break of paste electrode. Studies have reported that the use of small amounts of CTS $(0.5 \%)$ is enough for biopolymers application and that in some cases higher concentrations may affect the peak shape. ${ }^{18}$ However, there are reports about the use of 15 and $10 \%$ of this biopolymer when crosslinked with glutaraldehyde and epichlorohydrin. ${ }^{22,47}$ The electrolyte evaluated in $\mathrm{Pb}$ determination was $\mathrm{HNO}_{3}$ due to the fact that it presents an optimal voltammetric response to $\mathrm{Pb}^{52}$ Among the concentrations evaluated, $0.15 \mathrm{~mol} \mathrm{~L}^{-1}$ (Fig. S2, Supporting Information) was selected and used for subsequent studies, since the highest peak current $(11 \pm 0.7 \mu \mathrm{A})$ was obtained with it.

Influence of amplitude, frequency, deposition potential and interferences in the $\mathrm{Pb}$ voltammetric response

Between the deposition potential evaluated (from -1.3 to $-0.6 \mathrm{~V})$, the highest anodic peak current was obtained with $-1.1 \mathrm{~V}$ (Fig. S3, Supporting Information). Frequency (Fig. S4, Supporting Information) and amplitude (Fig. S5, Supporting Information) were also evaluated and the best results obtained were with the frequency of $80 \mathrm{~Hz}(1.13 \mu \mathrm{A} \pm 0.21)$ and $0.09 \mathrm{~V}$ of amplitude $(2.55 \mu \mathrm{A} \pm 0.57)$. These conditions were chosen for further experiments.

As, $\mathrm{Ba}, \mathrm{Be}, \mathrm{Cd}, \mathrm{Co}, \mathrm{Cu}, \mathrm{Cr}, \mathrm{Fe}, \mathrm{Hg}, \mathrm{Ni}, \mathrm{U}, \mathrm{V}$ and $\mathrm{Zn}$ were evaluated as interferences. Firstly, $50 \mu \mathrm{g} \mathrm{L}^{-1}$ of each compound was added in the cell and the voltammetric profile was obtained. After, $50 \mu \mathrm{g} \mathrm{L}^{-1}$ of $\mathrm{Pb}$ was added and the voltammogram was obtained. None of the possible interferences evaluated presented a voltammetric response in the working range applied and the presence of interferences did not affect the current response of $\mathrm{Pb}$ as shown in Fig. 8. When $\mathrm{Hg}$ was added, the voltammetric signal of $\mathrm{Pb}$ decreased nearly $1 \%$, but this decrease was not significant (Tukey Test with 95\% confidence). Thus, the studied interferents did not present interference in the voltammetric analysis demonstrating the selectivity of the electrode developed.

\section{Analytical performance and samples analysis}

After the optimization step for the $\mathrm{Pb}$ determination using GPE-CTS-TPP by SWASV, the method's analytical features

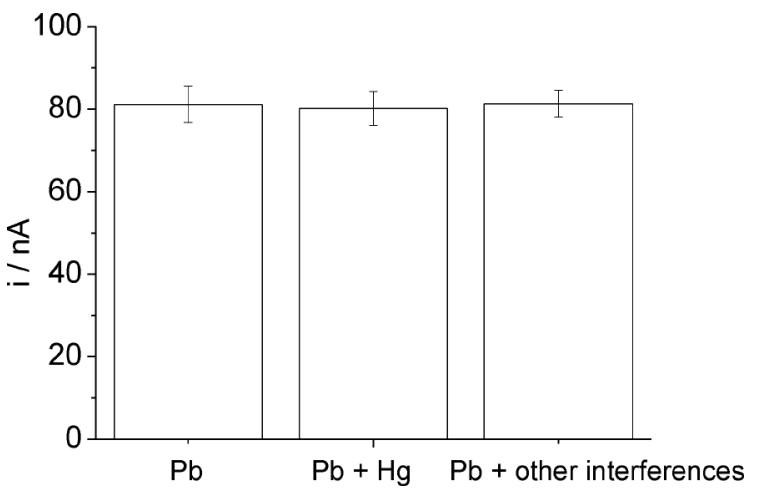

Fig. 8 Influence of interferences on the $\mathrm{Pb}$ oxidation peak current from GPE-CTS-TPP. Experimental conditions: $\mathrm{HNO}_{3} 0.15 \mathrm{~mol} \mathrm{~L}^{-1}$, $v=320 \mathrm{mV} \mathrm{s}^{-1}, E_{\text {dep }}=-1.1 \mathrm{~V}, E_{\text {start }}=-0.9 \mathrm{~V}, E_{\text {end }}=-0.1 \mathrm{~V}$, frequency $=80 \mathrm{~Hz}$ and amplitude $=0.09 \mathrm{~V}$.

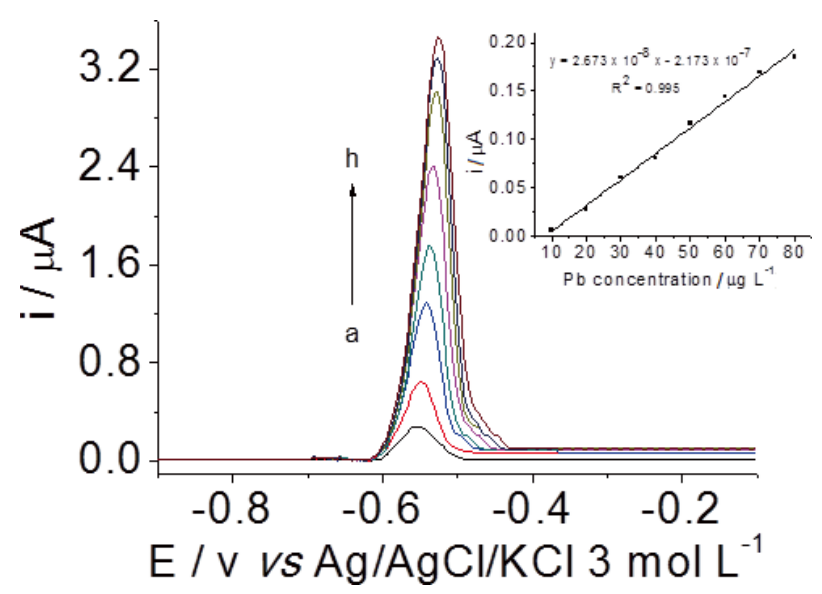

Fig. $9 \mathrm{~Pb}$ voltammograms obtained in GPE-CTS-TPP by SWASV. Experimental conditions: $\mathrm{HNO}_{3} 0.15 \mathrm{~mol} \mathrm{~L}^{-1}, v=320 \mathrm{mV} \mathrm{s}^{-1}, E_{\text {dep }}=$ $-1.1 \mathrm{~V}, t_{\text {dep }}=1020 \mathrm{~s}, E_{\text {start }}=-0.9 \mathrm{~V}, E_{\text {end }}=-0.1 \mathrm{~V}$, frequency $=80 \mathrm{~Hz}$ and amplitude $=0.09 \mathrm{~V}$. $(\mathrm{a}-\mathrm{h}) \mathrm{Pb}$ concentration from 10 to $80 \mu \mathrm{g} \mathrm{L}^{-1}$. Inset: analytical curve.

were evaluated. The concentration range was evaluated (from 10 to $80 \mu \mathrm{g} \mathrm{L}^{-1}$ ) and as it can be observed from the inset of Fig. 9, the regression curve obtained was linear $\left(R^{2}=0.995\right)$. The obtained LOD and LOQ of Pb by the proposed method were 0.73 and $2.44 \mu \mathrm{g} \mathrm{L}^{-1}$, respectively. In order to demonstrate the feasibility and the accuracy of the method proposed here, the $\mathrm{Pb}$ fortification was carried out in 3 samples (at 3 concentration levels) and the quantified concentrations by the proposed and by the comparative method are presented in Table 1. As it can be observed, the recoveries obtained by SWASV and HR-CS GF AAS were from 97 to $108 \%$ and from 96 to $111 \%$, respectively. Additionally, the concordance between the concentrations quantified by both methods are between 90 and $107 \%$, providing evidence of the method's accuracy.

Table 2 shows the comparisons of some analytical features of the proposed method with others already published. The methods developed by Sahoo et al. ${ }^{53}$ and Ashrafi et al..$^{54}$ presented similar LODs to ours. However, it is known that the synthesis of carbon nanotube can produce impurities such as amorphous carbon and metal particles of the catalysts present in the synthesis. ${ }^{55}$ On the other hand, many researchers have been studying how to solve this problem in nanotube synthesis, 
Table 1 Quantification of Pb in spiked samples with GPE-CTS-TPP by SWASV and HR-CS GF AAS

\begin{tabular}{|c|c|c|c|c|c|c|}
\hline \multirow{2}{*}{ Sample } & \multirow{2}{*}{$\begin{array}{l}\text { Concentration } \\
\text { added/ } \mu \mathrm{g} \mathrm{L}^{-1}\end{array}$} & \multicolumn{2}{|c|}{ Concentration quantified $\pm \mathrm{SD} / \mu \mathrm{g} \mathrm{L} \mathrm{L}^{-1}(\mathrm{RSD})$} & \multicolumn{2}{|c|}{ Recovery, \% } & \multirow{2}{*}{$\begin{array}{c}\text { Concordance, } \\
\%\end{array}$} \\
\hline & & SWASV & HR-CS GF AAS & SWASV & HR-CS GF AAS & \\
\hline \multirow[t]{3}{*}{$1^{\mathrm{a}}$} & 20 & $21.50 \pm 2.86(9.71)$ & $22.30 \pm 0.94(4.22)$ & 107 & 111 & 96 \\
\hline & 30 & $28.50 \pm 1.22(5.00)$ & $31.70 \pm 0.48(1.40)$ & 95 & 106 & 90 \\
\hline & 40 & $43.00 \pm 0.82(1.90)$ & $41.45 \pm 1.92(4.64)$ & 107 & 104 & 104 \\
\hline \multirow[t]{3}{*}{$2^{\mathrm{a}}$} & 20 & $19.70 \pm 1.25(7.06)$ & $21.10 \pm 1.22(5.55)$ & 98 & 105 & 93 \\
\hline & 30 & $29.70 \pm 2.05(7.71)$ & $32.66 \pm 0.80(2.33)$ & 99 & 109 & 91 \\
\hline & 40 & $41.30 \pm 6.02(14.56)$ & $38.49 \pm 6.02(15.65)$ & 103 & 96 & 107 \\
\hline \multirow[t]{3}{*}{$3^{\mathrm{b}}$} & 20 & $19.80 \pm 0.82(5.44)$ & $21.38 \pm 2.64(12.38)$ & 99 & 107 & 93 \\
\hline & 30 & $32.50 \pm 1.22(5.44)$ & $32.80 \pm 2.40(7.34)$ & 108 & 109 & 99 \\
\hline & 40 & $39.00 \pm 10.82(2.55)$ & $42.00 \pm 1.02(2.44)$ & 97 & 105 & 93 \\
\hline
\end{tabular}

a. Sparkling water. b. Still water. $n=3$.

Table 2 Analytical features of methods applied to $\mathrm{Pb}$ determination

\begin{tabular}{|c|c|c|c|c|}
\hline Electrode & Technique & $\mathrm{LOD} / \mu \mathrm{g} \mathrm{L} \mathrm{L}^{-1}$ & Linear range $/ \mu \mathrm{g} \mathrm{L}^{-1}$ & Reference \\
\hline Zeolite $\mathrm{NH}_{4}$-Y/carbon paste electrode & $\mathrm{CV}^{\mathrm{a}}$ & 3.6 & $5.18-20.72$ & 63 \\
\hline Graphene oxide/bismuth/carbon paste electrode & DPASVb & 0.55 & $20-120$ & 53 \\
\hline Triphenylphosphine/multiwalled carbon nanotubes/ionic liquid/carbon paste electrode & SWASVc & 12.43 & $0.021-31.08$ & 64 \\
\hline $\mathrm{Bi} / \mathrm{Cu} /$ screen-printed electrodes & SWASV & 172 & $269.4-2693$ & 64 \\
\hline Antimony nanoparticle-multiwalled carbon nanotubes/carbon paste electrode & SWASVc & 0.65 & $10-60$ & 54 \\
\hline Multiwalled carbon nanotubes/poly(1,5-diaminonaphthalene)/platinum electrode & SWASV $^{\mathrm{c}}$ & 2.1 & $4-150$ & 65 \\
\hline Bismuth-xerogel/Nafion/glassy carbon electrode & SWASV & 1.3 & $1.04-20.72$ & 66 \\
\hline Bismuth powder/carbon paste electrode & SWASVc & 0.9 & $10-100$ & 67 \\
\hline Bismuth-modified carbon nanotube electrode & SWASV & 1.3 & $2-100$ & 68 \\
\hline Chitosan crosslinked with sodium tripolyphosphate/graphite paste electrode & SWASV & 0.73 & $10-80$ & This work \\
\hline
\end{tabular}

a. Cyclic voltammetry. b. Differential pulse anodic stripping voltammetry. c. Square-wave anodic stripping voltammetry.

as well as reduce its cost, improve synthesis efficiency and mass production. ${ }^{56}$ In addition, the work developed by Ashrafi et al. ${ }^{54}$ used antimony nanoparticles that are synthesized with toxic reagents, such as dimethylformamide, that can cause various health problems..$^{57,58}$ Moreover, Sahoo et al. ${ }^{53}$ used graphene oxide to produce the electrode applied for the determination of $\mathrm{Pb}^{53}$ It is known that the production of graphene oxide presents a high cost and the obtained material can present low electrical conductivity (when compared to its graphene precursor) due to the partial disruption of the $\mathrm{sp}^{2}-\mathrm{sp}^{2}$ type bonds, resulting in sheets with carbons having type $\mathrm{sp}^{2}-\mathrm{sp}^{3}$, making it less stable and dispersible in aqueous medium. ${ }^{59}$

Considering these factors and the ease of obtaining graphite paste electrode with TPP crosslinked chitosan, it is believed that the method proposed here offers considerable potential of applicability in the determination of $\mathrm{Pb}$ in different samples.

Finally, since the method was accurate, it was applied to $\mathrm{Pb}$ determination in water samples (sparkling and still water) and the metal was not detected in the samples (the samples were also analyzed by comparative method and the $\mathrm{Pb}$ was not detected). Therefore, these samples can be recommended for consumption once they are in accordance with the $\mathrm{Pb}$ limit, which is $0.01 \mathrm{mg} \mathrm{L}^{-1} \cdot{ }^{60-62}$

\section{Conclusions}

With the results presented in this work, it is possible to infer that the TPP crosslinked CTS presents a surface with good morphological properties and greater stability when compared to chitosan without crosslinking. With the results of the electrochemical characterization, it was possible to observe that the GPE-CTS-TPP presented a quasireversible process, lower resistance and higher electron transfer rate, indicating the possibility of its application in the determination of $\mathrm{Pb}$ in samples of mineral water. Additionally, the electrochemical process that occurs between $\mathrm{Pb}$ and the chitosan crosslinked with TPP is controlled by adsorption.

\section{Acknowledgements}

We are grateful for SEM analysis performed in the Centro de Microscopia Eletrônica do Sul (CEME-SUL) of Universidade Federal do Rio Grande (FURG). We would also like to thank CAB English Lessons for the English text correction. This work was financed in part by the Coordenação de Aperfeiçoamento de Pessoal de Nível Superior (CAPES), Brazil (Finance Code 001).

\section{Supporting Information}

The Supporting Information provides important results related to voltammetric parameters optimization.

\section{References}

1. D. Lowinsohn and M. Bertotti, Quím. Nova, 2006, 29, 1318.

2. J. Wang, "Analytical Electrochemistry", 2000, Wiley-VCH, Canada.

3. A. C. Pereira, A. S. Santos, and L. Kubota, Quím. Nova, 2002, 25, 787.

4. M. D. P. T. Sotomayor, A. A. Tanaka, R. S. Freire, and L. T. Kubota, Encycl. Sens., 2006, 1, 195.

5. J. V. Maciel, A. M. M. Durigon, M. M. Souza, R. F. N. 
Quadrado, A. R. F. Fajardo, and D. Dias, Trends. Environ. Anal. Chem., 2019, 22, e00062.

6. M. R. Pacheco, S. C. Barbosa, R. F. N. Quadrado, A. R. Fajardo, and D. Dias, Anal. Bioanal. Chem., 2019, 411, 3269.

7. C. Damian, L. H. Beirão, A. de Francisco, M. L. P. Espírito Santo, and E. Teixeira, Aliment. Nutr., 2005, 16, 195.

8. G. Crini and P. M. Badot, Prog. Polym. Sci., 2008, 33, 399.

9. C. P. Pinheiro, T. G. Mello, M. L. G. Vieira, and L. A. A. Pinto, Environ. Sci. Pollut. Res., 2018, https://doi.org/ 10.1007/s11356-019-04905-9.

10. E. Guibal, Sep. Purif. Technol., 2004, 38, 43.

11. W. S. WanNgah, L. C. Teong, and M. A. K. M. Hanafiah, Carbohydr. Polym., 2011, 83, 1446.

12. L. Vitali, I. C. Vieira, and A. Spinelli, Food Chem., 2011, $126,807$.

13. A. Shweta and P. Sonia, Int. Res. J. Pharm., 2013, 4, 45.

14. R. S. Vieira and M. M. Beppu, Colloids Surf., A, 2006, 279, 196.

15. W. Fan, W. Yan, Z. Xu, and H. Ni, Colloids Surf., B, 2012, 90, 21.

16. F. L. Mi, S. S. Shyu, C. Y. Kuan, S. T. Lee, K. T. Lu, and S. F. Jang, J. Polym. Sci., 1999, 74, 1868.

17. M. Yang, Y. Yang, B. Liu, G. Shen, and R. Yu, Sens. Actuators., B, 2004, 101, 269.

18. G. Lu, X. Yao, X. Wu, and T. Zhan, Microchem. J., 2001, 69, 81 .

19. A. Wong, M. R. V. Lanza, and M. D. P. T. Sotomayor, Comb. Chem. High Throughput Screening, 2010, 13, 666.

20. D. Kiziltan, T. Vural, C. Bayram, S. Ozturk, B. Bozdogan, Y. T. Yaman, S. Abaci, and E. B. Denkbas, Anal. Sci., 2018, 34, 789.

21. E. S. Paik, Y. R. Kim, and H. G. Hong, Anal. Sci., 2018, 34, 1271.

22. M. del Valle, Sensors, 2011, 11, 10180.

23. K. Kalcher, Electroanalysis, 1990, 2, 419.

24. D. de Souza, L. C. Melo, A. N. Correia, P. de Lima-Neto, O. Fatibello-Filho, and L. H. Mascaro, Quim. Nova, 2011, $34,487$.

25. A. C. Boni, M. D. P. T. Sotomayor, M. R. V. Lanza, S. M. C. N. Tanaka, and A. A. Tanaka, J. Braz. Chem. Soc., 2010, $21,1377$.

26. R. L. Mccreery, Chem. Rev., 2008, 108, 2646.

27. A. M. Brett and C. M. Brett, "Electrochemistry: Principle, Methods and Applications", 1993, Oxford, New York.

28. B. Uslu and S. Ozkan, Comb. Chem. High Throughput Screening, 2007, 10, 495.

29. G. G. Wildgoose, H. C. L. C. E. Banks, and R. G. Compton, Microchim. Acta, 2006, 152, 187.

30. G. G. Wildgoose, S. J. Wilkins, G. R. Williams, R. R. France, D. L. Carnahan, L. Jiang, T. G. J. Jones, and R. G. Compton, Chem. Phys. Chem., 2005, 6, 352.

31. I. Svancara, K. Kalcher, A. Walcarius, and K. Vytras, "Electroanalysis with Carbon Paste Electrodes", 2012, CRC Press Taylor \& Francis Group, United States.

32. S. C. Fernandes, I. R. W. Z. de Oliveira, O. Fatibello-Filho, A. Spinelli, and I. C. Vieira, Sens. Actuators, B, 2008, 133, 202.

33. N. Eladlani, E. M. Dahmane, M. Rhazi, M. Taourirte, and Y. Habibi, Fresenius Environ. Bull., 2014, 23, 3278.

34. A. R. Raut and S. R. Khairkar, World. J. Pharm. Res., 2014, 3,523 .

35. B. Hu, C. Pan, Y. Sun, Z. Hou, H. Ye, B. Hu, and X. Zeng, J. Agric. Food Chem., 2008, 56, 7451.

36. R. M. Silverstein, F. X. Webster, and D. J. Kiemle, "Spectrometric Identification of Organic Compounds", 2007, LTC, Rio de Janeiro (in Portuguese).

37. M. Arshadi, M. Ghiaci, A. A. Ensafia, H. Karimi-Maleha, and S. L. Suibb, J. Mol. Catal. A: Chem., 2011, 338, 71.
38. A. A. Ensafi, H. Karimi-Maleh, M. Ghiaci, and M. Arshadi, J. Mater. Chem., 2011, 21, 15022.

39. Y. Chen, G. Zheng, Q. Shi, R. Zhao, M. Chen, Sens. Actuators, B, 2018, 277, 289.

40. F. Wang and S. Hu, J. Electroanal. Chem., 2005, 580, 68.

41. P. B. Deroco, R. C. Rocha-Filho, and O. Fatibello-Filho, Talanta, 2018, 179, 115.

42. J. Merrifield, W. G. Davids, J. D. Macrae, and A. Amirbahman, Water Res., 2004, 38, 3132.

43. F. Scholz, "Eletroanalytical Methods", 2010, Springer Heidelberg Dordrecht, Nova York.

44. A. J. Bard, G. Inzelt, and F. Scholz, "Electrochemical Dictionary", 2008, Springer-Verlag Berlin Heidelberg, Berlin.

45. B. C. Janegitz, L. C. S. Figueiredo-Filho, L. H. MarcolinoJunior, S. P. N. Souza, E. R. Pereira-Filho, and O. FatibelloFilho, J. Electroanal. Chem., 2011, 660, 209.

46. B. C. Janegitz, L. H. Marcolino Jr, and O. Fatibello-Filho, Quim. Nova, 2007, 30, 1673.

47. I. R. W. Z. de Oliveira and I. C. Vieira, Quim. Nova, 2006, 29,932

48. N. Ben-Shalom, N. Kudabaeva, and M. Borisover, Chemosphere, 2005, 59, 1309.

49. D. Talarico, F. Arduini, A. Amine, I. Cacciotti, D. Moscone, and G. Palleschi, Anal. Bioanal. Chem., 2016, 408, 7299.

50. D. S. Karousos, K. I. Desdenakis, P. M. Sakkas, G. Sourkouni, B. G. Pollet, and C. Argirusis, Ultrason. Sonochem., 2017, 35, 591.

51. Brazil, Conductive materials, http://www.labspot.ufsc. br/ jackie/cap3_new.pdf.

52. F. C. Vicentini, T. A. Silva, A. Pellatieri, B. C. Janegitz, O. Fatibello-Filho, and R. C. Faria, Microchem. J., 2014, 116, 191.

53. P. K. Sahoo, B. Panigrahy, S. Sahoo, A. K. Satpati, D. Li, D. Bahadur, Biosens. Bioelectron., 2013, 43, 293.

54. A. M. Ashrafi, S. Cerovac, S. Mudric, V. Guzsvány, L. Husáková, I. Urbanová, and K. Vytras, Sens. Actuators, B, 2014, 191, 320.

55. M. H. Herbst, M. I. F. Macêdo, and A. M. Rocco, Quim. Nova, 2004, 27, 986.

56. A. T. Lawal, Mater. Res. Bull., 2016, 73, 308.

57. D. Rui, C. Daojun, and Y. Yongjian, Environ. Toxicol. Pharmacol., 2011, 31, 357.

58. H. Y. Chang, T. S. Shih, Y. L. Guo, C. Y. Tsai, and P. C. Hsu, Fertil. Steril., 2004, 81, 1589.

59. D. R. Dreyer, S. Park, C. W. Bielawski, and R. S. Ruof, Chem. Soc. Rev., 2010, 39, 228.

60. Brazil, Ministério da Saúde, Portaria n 2914. http://bvsms. saude.gov.br/bvs/saudelegis/gm/2011/prt2914_12_12_2011.html.

61. Brazil, Ministério do Meio Ambiente, Resolução n ${ }^{\circ}$ 357. http:// www.mma.gov.br/port/conama/res/res05/res35705.pdf.

62. World Health Organization, Guidelines for Drinking-water Quality, Switzerland, http://apps.who.int/iris/bitstream/10665/ 44584/1/9789241548151_eng.pdf.

63. S. Senthilkumar and R. Saraswathi, Sens. Actuators, B, 2009, 141, 65.

64. H. Bagheri, A. Afkhami, H. Khoshsafar, M. Rezaei, and A. Shirzadmehr, Sens. Actuators, B, 2013, 186, 451.

65. H. D. Vu, L. H. Nguyen, T. D. Nguyen, H. B. Nguyen, T. L. Nguyen, and D. L. Tran, Ionics, 2014, http://dx.doi. org/10.1007/s11581-014-1199-8.

66. A. D. Panagiotis and I. P. Mamas, Anal. Chim. Acta, 2013, 769, 49

67. S. B. Hocevar, I. Svancara, K. Vytras, and B. Ogorevc, Electrochim. Acta, 2005, 51, 706.

68. G. H. Hwang, W. K. Han, J. S. Park, and S. G. Kang, Talanta, 2008, 76, 301. 